Article

\title{
Forecasting China's Coal Power Installed Capacity: A Comparison of MGM, ARIMA, GM-ARIMA, and NMGM Models
}

\author{
Shuyu $\mathrm{Li}^{1}$, Xue Yang ${ }^{1}$ and Rongrong $\mathrm{Li}^{1,2, *}$ \\ 1 School of Economic and Management, China University of Petroleum (East China), Qingdao 266580, \\ China; lishuyu201712@126.com (S.L.); yangxue1y2x@163.com (X.Y.) \\ 2 School of Management \& Economics, Beijing Institute of Technology, Haidian District, Beijing 100081, China \\ * Correspondence: lirr@upc.edu.cn; Tel.: +86-532-8698-3286
}

Received: 25 January 2018; Accepted: 11 February 2018; Published: 13 February 2018

\begin{abstract}
Construction of new coal-fired power plants in China has posed a huge challenge to energy sustainability. Forecasting the installed capacity more accurately can serve to develop better energy sustainability strategy. A comparison between linear and non-linear forecasting models can more comprehensively describe the characteristics of the prediction data and provide multi-angle analysis of the prediction results. In this paper, we develop four time-series forecasting techniques-metabolism grey model (MGM), autoregressive integrated moving average (ARIMA), grey model (GM)-ARIAM, and nonlinear metabolism grey model (NMGM)—for better forecasting of coal-fired power installed capacity. The average relative errors between the simulation and actual data of the MGM, GM-ARIMA, ARIMA, and NMGM model are $3.37 \%, 2.13 \%, 3.71 \%$ and $2.36 \%$ respectively, which indicate those four models can produce highly accurate results. The forecasting results show the average annual growth rate of China's coal-fired power installed capacity in the next ten years (2017-2016) will be $5.26 \%$ a year, which is slower than the average annual growth rate $(8.20 \%$ a year) for 2007-2016. However, the average annual new added installed capacity for 2017-2026 will be 74 gigawatts, which is higher than the average annual added installed capacity (56 gigawatts) for 2007-2016.
\end{abstract}

Keywords: China; coal-fired power; forecasting; linear and nonlinear model

\section{Introduction}

Construction of new coal-fired power plants has seriously challenged energy sustainability [1-5]. This is especially true for China [6-8]. From 2000 to 2015, China built about 724 GW of coal-fired power generation capacity, which is the largest coal-fired power generation expansion in human history [9]. China's over-construction of coal-fired power plants has challenged the sustainably of energy, environmental and climate $[8,10,11]$. On the one hand, it has weakened the positive effect of energy transformation on the optimization of energy structure, leading to the rapid increase of energy consumption $[8,12,13]$. On the other hand, thermal power generation has increased carbon emissions and caused serious pollution to the atmosphere. The waste gas, water and residue emitted by thermal power plants not only endanger the health of human beings, but also have high treatment costs and serious environmental pollution $[10,13,14]$. According to statistics, even if China does not build new coal-fired power plants any more, the carbon emissions of existing coal-fired power plants will be $150 \%$ higher than that required to limit global warming to 2 degrees Celsius $[6,13,15]$.

To a certain extent, the installed capacity of the power system represents the development of electricity supply and demand in China $[6,8,12,13]$. In addition to reflecting the amount of energy consumed in a country, the installed capacity of thermal power can also reflect the level of the 
low-carbon economy and carbon emissions in the industrial sector. Besides, the number of coal-fired power plants in China is at the highest level in the world [7,8,12]. Thus, its coal-fired power plants will impose a significant impact on local energy consumption and world carbon emissions. Based on this, accurate prediction can effectively schedule and plan the energy system, improve the reliability and reduce the operating cost. To sum up, the prediction of China's future thermal power installed capacity will be conducive to a comprehensive understanding of China's energy transformation and low-carbon economic development $[6,12]$. In addition, forecasting its growth rate will provide a reference for the scale of the global coal-fired power plant and the changes in carbon emissions.

The data used in this paper come from China Statistical Yearbook 2017. Multiple prediction methods will be used simultaneously to predict in this study. Linear models, such as the metabolic grey model (GM), autoregressive integrated moving average (ARIMA) model, GM-ARIMA model, and non-linear metabolic grey models are adopted to analyze the thermal power installed capacity period 2000-2016 and predict that over the next decade. Through the comparison of various methods, we can analyze and predict the data from two angles of linearity and nonlinearity. Multi-angle analysis will make the prediction more persuasive. In the measurement of model accuracy, this paper will use average relative error as a criterion. Accuracy can clearly illustrate the reference value of this forecast work.

The structure of this article is as follows: The second section is a literature review. The third section is the methodology, including two hybrid-linear models and one non-linear model. The fourth section is forecasting results and optimality analysis. The fifth section summarizes the whole paper.

\section{Literature Review}

The energy needs of a power system must be evaluated by forecasting models with high-precision. In the current research, the prediction model chosen by the researcher is usually determined by the data type. For example, some data are suitable for simulations using linear time series. By contrast, some data are suitable for nonlinear time series. Currently, most of the methods adopted in those articles were simple linear models or simple nonlinear models.

In the field of energy forecasting, the applications of linear prediction models are mostly focused on the grey model, neural network model and ARIMA model [16-20]. In these studies, the traditional grey model has been developed to Rolling-ALO-GM $(1,1)$ and so on. The inclusion of the grey prediction model [19] of the rolling mechanism made the timeliness of the data series reflect more clearly. The inear neural network model [21] is a new linear prediction method that uses neural networks to determine model weights. The ARIMA model [20] can reflect the characteristics of a data sequence in self-similarity, periodicity and suddenness. After the application of prediction of electricity generation, the error produced by the ARIMA model is less than $3 \%$. Besides, the ARIMA model is highly adaptable in predicting non-stationary sequences. In addition to the field of energy research, this approach is also applicable to the prediction of non-stationary behavior in the field of agrifood and health. The adaptive MA model has been assessed and forecasted in vineyard management and health care structures [22,23]. Based on the above three models, scholars have successively proposed the following complex linear model. A variable-spread fuzzy linear regression model $[24,25]$ is a forecasting method of constructing the membership function of the fuzzy regression coefficient, so that the fuzziness of the input information can be avoided to a certain extent. The pattern-based local linear regression model [26-28] simplifies the prediction problem by filtering the trend of the period and the season. It provided better extrapolation properties for short-term load forecasting. A partial functional linear regression model [29] has been used to forecast the daily power output of photovoltaic systems.

In addition, the non-linear prediction model has also been widely used for forecasting power demand. The nonlinear prediction models developed by scholars and put into application are as follows. The BP neural network model [30-32] can clearly reflect the relationship between the influencing factors. It has been widely used in the forecasting field and has a high degree of accuracy. The non-linear multivariable regression method [33-35] has achieved better predictive effect than 
classical ones. It has been applied for midterm load forecasting in the Greek power system. Based on the GM $(1,2)$ model, the non-linear grey multivariable NGM $(1,2)$ model [36-39] was proposed for energy field forecasting. The introduction of power coefficient makes this non-linear grey model have the ability to reflect the nonlinear influence mechanism. Non-linear ARMA model $[40,41]$ has a clear precision advantage in one-step-ahead forecasting and has recently been applied to the prediction of electric energy.

Few studies have combined linearity and non-linearity to predict and analyze research subjects. Since most of the data is not characterized by a single linear or non-linearity, combining multiple predictive models with linear and non-linearity will make the final prediction more flexible and practical. In this paper, we will introduce the metabolic grey model (MGM model), autoregressive integrated moving average model (ARIMA model), GM-ARIMA model and nonlinear metabolic grey model (NMGM model) simultaneously to forecast China's thermal power installed capacity.

\section{Methodology}

In this section, we first introduce the formula derivation and modeling principle of the MGM model, ARIMA model, GM-ARIMA model and nonlinear metabolic grey model. We take a graphic and textual way to explain the operation in detail. For ease of understanding, we use Table 1 to explain the meaning of the notations contained in the following formulas. In addition, the final part of this section will present formulas for measuring the accuracy of a predictive model.

Table 1. Explanation of the symbols in the following formulas.

\begin{tabular}{cccc}
\hline Notations & Explanation & Notations & Explanation \\
\hline$x^{(0)}(k)$ & Original sequence & ${ }^{\prime} c^{\prime}$ & Constant term \\
$x^{(1)}(k)$ & Once accumulated sequence & $\alpha_{i}, \beta_{i}$ & Harmonic parameter \\
$\hat{x}^{(0)}(k)$ & Prediction of raw sequence & $u_{t}$ & Error term of early data \\
$\hat{x}^{(1)}(k)$ & Prediction of 1-AGO sequence & $Y_{t}$ & Initial data sequence \\
$B$ & Matrix of data and constants & $Y_{t}^{*}$ & Predicted data sequence \\
$Y$ & Matrix of data & $' d^{\prime}$ & Order of the difference \\
$t$ & Time sequence & $' p^{\prime}$ & Order of autoregressive process \\
${ }^{\prime} a^{\prime}, b^{\prime}$ & Constant parameter & $' q^{\prime}$ & Order of moving average process \\
$Z^{(0)}(k)$ & Residual sequence & $\alpha$ & Power coefficient \\
\hline
\end{tabular}

\subsection{MGM (1,1) Model}

The metabolic grey model uses the time series itself to describe the changes in future data. In other words, the MGM $(1,1)$ model uses its own data sequence for function evolution and prediction.

Assume that the existing time series can be expressed as: $X^{(0)}=\left\{x^{(0)}(1), x^{(0)}(2), \ldots, x^{(0)}(n)\right\}$. In order to get the stationary sequence, we take the accumulation tool: $x^{(1)}(k)=\sum_{i=1}^{k} x^{(0)}(i)$, to get a cumulative sequence. The 1-AGO sequence is: $X^{(1)}=\left\{x^{(1)}(1), x^{(1)}(2), \ldots, x^{(1)}(n)\right\}$. After the accumulation, the $X^{(1)}$ sequence is trends more on the image and the linear equations can be more strongly explained.

Based on this, as long as the expression of the trend series can be solved, the future forecast data can be known. After repeated experiments, we found that the first-order accumulation sequence complies with the following equation [42].

$$
\frac{d x^{(1)}}{d t}+a x^{(1)}=b
$$


Equation (1) represents a linear regression formula that satisfies the time series $X^{(1)}$. After using the data formula to derive, the solution of Equation (1) can be calculated by the following formula.

$$
\hat{x}^{(1)}(k)=\left[x^{(0)}(1)-\frac{b}{a}\right] e^{-a(k-1)}+\frac{b}{a}, \quad k=1,2, \ldots, n
$$

In Equation (2), as long as the coefficients ' $a$ ' and ' $b$ ' can be solved, the solution to the sequence $\hat{x}^{(1)}(k)$ can be solved. The calculation results show that the coefficients ' $a$ ' and ' $b$ ' satisfy the following Equation (3). Equation (3) explains the unknown quantity ' $a$ ' and ' $b$ ' in terms of matrix ' $B$ ' and ' $Y$ ', which have been responded by Equations (4) and (5).

$$
\begin{gathered}
{[a, b]^{T}=\left(B^{T} B\right)^{-1} B^{T} Y} \\
Y_{N}=\left[x^{(0)}(2), x^{(0)}(3), \ldots, x^{(0)}(n)\right]^{T} \\
B=\left[\begin{array}{cc}
-\left(0.5 x^{(1)}(2)+0.5 x^{(1)}(1)\right) & 1 \\
-\left(0.5 x^{(1)}(3)+0.5 x^{(1)}(2)\right) & 1 \\
\vdots & \vdots \\
-\left(0.5 x^{(1)}(n)+0.5 x^{(1)}(n-1)\right) & 1
\end{array}\right]
\end{gathered}
$$

In the last step, we substitute the values of ' $B$ ' and ' $Y$ ' into Equation (3) and substitute the values of ' $a$ ' and ' $b$ ' into Equation (2). With the solution of Equation (2), the value of the predicted data sequence $\hat{x}^{(0)}(k)$ can be obtained by subtraction of the sequence $\hat{x}^{(1)}(k)$, which is shown as Equation (6).

$$
\hat{x}^{(0)}(k)=\hat{x}^{(1)}(k)-\hat{x}^{(1)}(k-1)=\left[x^{(0)}(1)-\frac{b}{a}\right]\left(1-e^{a}\right) e^{-a(k-1)}, \quad k=2,3, \ldots, n
$$

\subsection{ARIMA Model}

Autoregressive integrated moving average (ARIMA) model is composed of two models. An autoregressive (AR) model is designed to predict future data based on past data values of smooth time-series. A moving average (MA) model aims to make judgments about future data trends based on the error of the fit data. According to the respective characteristic of the AR model and the MA model, the ARIMA model will give specific parameters to the time series. The parameters ' $p$ ' and ' $q$ ' are the lag orders of the MA model and the AR model, which can be identified by autocorrelation function (ACF) and partial autocorrelation function (PACF). In addition, parameter ' $d$ ' represents the number of differentials that make the sequence stable. Thus, we can define the ARIMA model as ARIMA $(p, d, q)[43]$.

Assume that the initial data sequence is: $Y_{t}=\left\{y_{1}^{0}, y_{2}^{0}, \cdots y_{m}^{0}\right\}$, where $y_{k}^{0}$ means the raw data block. Assume that the predicted data sequence is: $Y_{t}^{*}=\left\{y_{1}^{1}, y_{2}^{1}, \cdots y_{m}^{1}\right\}$, where the $y_{k}^{1}$ means the forecasting data block. Equation (7) is the complete ARIMA modeling equation. It should also be emphasized that Equations (8) and (9) are the formulas of the AR model and the MA model.

$$
\begin{gathered}
Y_{t}^{*}=c+\alpha_{1} Y_{t-1}+\alpha_{2} Y_{t-2}+\cdots+\alpha_{k} Y_{t-k}+\mu_{t}+\beta_{1} \mu_{t-1}+\beta_{2} \mu_{t-2}+\cdots+\beta_{q} u_{t-q} \\
Y_{t}^{*}=c+\alpha_{1} Y_{t-1}+\alpha_{2} Y_{t-2}+\cdots+\alpha_{p} Y_{t-p}+u_{t} \\
Y_{t}^{*}=u_{t}+\beta_{1} u_{t-1}+\beta_{2} u_{t-2}+\cdots+\beta_{q} u_{t-q}
\end{gathered}
$$

In the process of solving the sequence, we find that the predicted sequence $Y_{t}^{*}$ can be represented by the original sequence $Y_{t}$, which is shown as the following Equation (10). In this equation, ' $d$ ' represents the order of the difference. Besides, matrix ' $B$ ' can be expressed by Equation (11). 
Putting this sequence formula into the software for planning solution, we can get the final predictive value.

$$
\begin{gathered}
Y_{t}^{*}=(1-B)^{d} Y_{t} \\
B=\left(\begin{array}{cc}
-\left(y_{1}^{1}+y_{2}^{1}\right) / 2 & 1 \\
\vdots & \vdots \\
-\left(y_{m-1}^{1}+y_{m}^{1}\right) / 2 & 1
\end{array}\right)
\end{gathered}
$$

\subsection{GM-ARIMA Model}

The GM-ARIMA model has been used in the prediction of the energy field with good accuracy [44]. The reason for choosing this model for our prediction is that GM-ARIMA can reflect the correction of linear prediction. Since the GM-ARIMA model is a combination of the GM model and ARIMA model, its derivation can draw on this two parts. The predictive value of the combined model is obtained by two processes of prediction and residual correction. Among them, the GM model is used for initial prediction, and the ARIMA model is used for residual correction.

Figure 1 shows the overall process of GM-ARIMA model calculation. As shown in Figure 1, the overall plan of the GM-ARIMA model consists of the following four steps:

The GM model is used to predict the data, and the initial prediction value is obtained.

The predicted values are compared with the actual data, and the residual is calculated.

The residual sequence is smoothed and the parameters ' $p$ ' and ' $q$ ' are determined from the correlation ACF and PACF plot. The ARIMA model is used to obtain a modified residual sequence.

The new residual sequence is added to the initial forecast value, and the final forecast value can be obtained.

The specific calculation process is shown below.

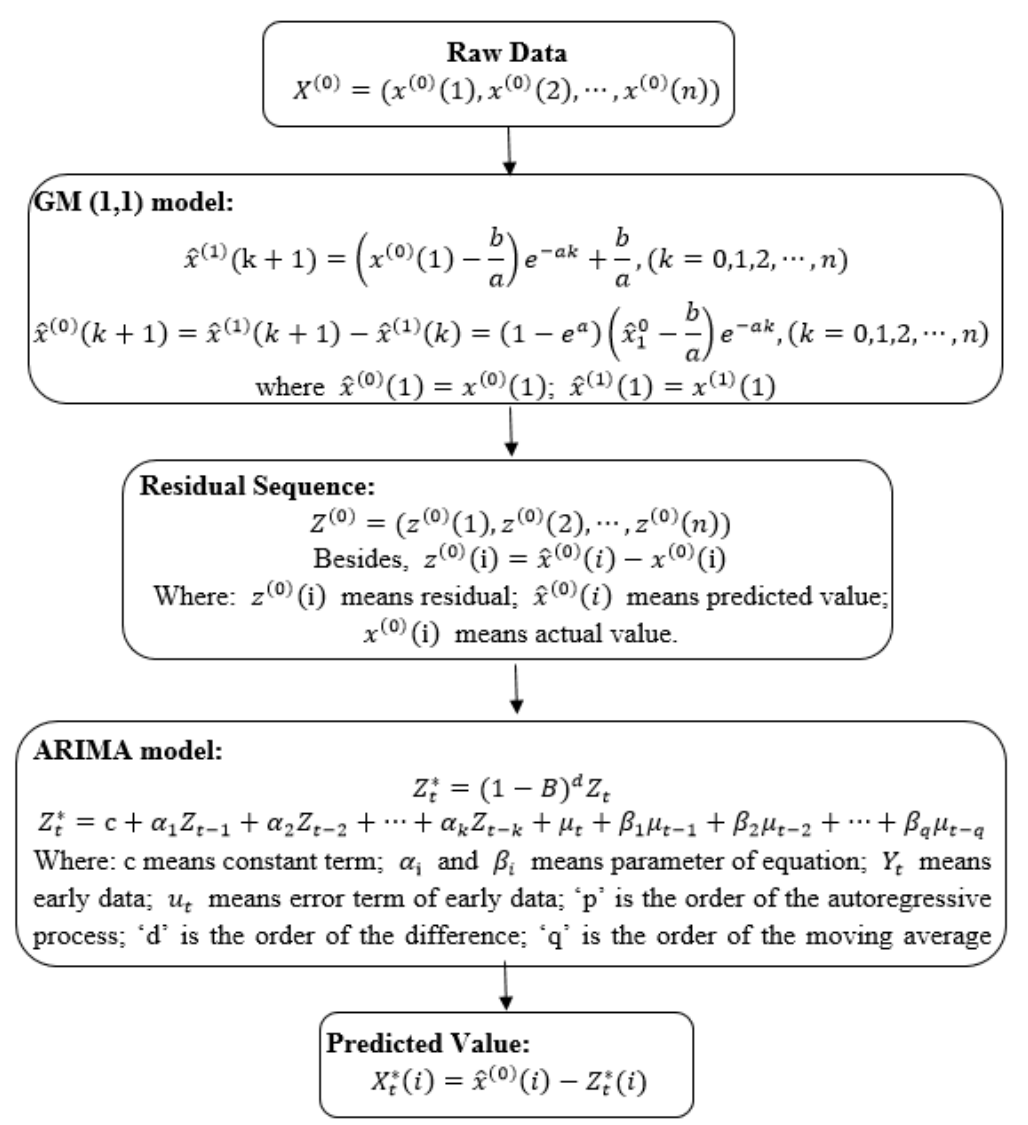

Figure 1. Calculation formula and flow chart of GM-ARIMA Model. 


\subsection{Non-Linear Metabolic Grey Model}

We use non-linear metabolic grey model as the nonlinear prediction method in this paper. Compared with linear metabolic grey model, the addition of power coefficients ' $\alpha$ ' is the key to converting linearity to nonlinearity [45].

We define $x^{(0)}(k)$ as original data sequence, $x^{(1)}(k)$ as accumulate data sequence. The core equation of the nonlinear grey model is shown below.

$$
\begin{gathered}
x^{(0)}(k)+a\left(Z^{(1)}(k)\right)^{\alpha}=b \\
Z^{(1)}(k)=0.5 x^{(1)}(k)+0.5 x^{(1)}(k-1)
\end{gathered}
$$

First, the first-order accumulation sequence satisfies the following differential equation.

$$
\frac{d x^{(1)}(t)}{d t}+a\left(x^{(1)}(t)\right)^{\alpha}=b
$$

Then, determine the meaning of the unknown variables in the above equation.

$$
\begin{gathered}
\hat{\alpha}=[a, b]^{T}=\left(B^{T} B\right)^{-1} B^{T} Y \\
B=\left(\begin{array}{cc}
-\mathbf{Z}^{(\mathbf{1})}(\mathbf{2})^{\alpha} & \mathbf{1} \\
-\mathbf{Z}^{(\mathbf{1})}(\mathbf{3})^{\alpha} & \mathbf{1} \\
\vdots & \vdots \\
-\mathbf{Z}^{(\mathbf{1})}(\mathbf{n})^{\boldsymbol{\alpha}} & \mathbf{1}
\end{array}\right) \\
Y=\left(\begin{array}{c}
x_{2}^{0} \\
\vdots \\
x_{m}^{0}
\end{array}\right)
\end{gathered}
$$

Based on these variables that have been explained, we use the Fourth-order Runge-Kutta to solve the solution of Equation (13) and get the value of $x^{(1)}(t)$.

Fourth-order Runge-Kutta is shown below. With the help of Lingo software, the final solution of Equation (13) and $\hat{x}^{(1)}(k)$ can be calculated.

$$
\begin{gathered}
\frac{d X}{d t}=F(t, X) \\
\left\{\begin{array}{c}
K_{1}=F\left(t_{n}, X_{n}\right) \\
K_{2}=F\left(t_{n}+\frac{h}{2}, X_{n}+\frac{h}{2} K_{1}\right) \\
K_{3}=F\left(t_{n}+\frac{h}{2}, X_{n}+\frac{h}{2} K_{2}\right) \\
K_{4}=F\left(t_{n}+h, X_{n}+h K_{3}\right) \\
X_{n+1}=X_{n}+\frac{h}{6}\left[K_{1}+2 K_{2}+2 K_{3}+K_{4}\right]
\end{array}\right.
\end{gathered}
$$

Finally, as the value of $\hat{x}^{(1)}(k)$ has been already known, final predicted value $\hat{x}^{(0)}(k)$ can be obtained by the accretion as Equation (18).

$$
\hat{x}^{(0)}(k+1)=\hat{x}^{(1)}(k+1)-\hat{x}^{(1)}(k)
$$

\subsection{Measurement of the Forecasting Performance}

In this study, we compared the accuracy of the different models using the fitted data. Due to the fact that there is a real data reference for fitting the data, we can use the contrast between the two to calculate the exact error value. The more common error value formula has the following. In these error 
formulas, we define ' $y_{i}{ }^{\prime}{ }^{\prime} x_{i}{ }^{\prime}{ }^{\prime} n$ ' as fitting value, true value and sample size, respectively. Detailed error judgment indicators are mean absolute percent error (MAPE), mean square percent error (MSPE) and mean square error (MSE).

$$
\begin{gathered}
\text { MSE }=\frac{1}{n} \sum_{i=1}^{n}\left(y_{i}-x_{i}\right)^{2} \\
\text { MSPE }=\frac{1}{n} \sqrt{\sum_{i=1}^{n}\left[\frac{y_{i}-x_{i}}{x_{i}}\right]^{2}} \\
\text { MAPE }=\frac{1}{n} \sum_{i=1}^{n} \frac{y_{i}-x_{i}}{x_{i}}
\end{gathered}
$$

\section{Empirical Results}

\subsection{Display of Thermal Power Capacity}

The data period 2000-2016 selected in this paper is from the Chinese Statistical Yearbook. As shown in Figure 2, in the past twenty years, China's thermal power installed capacity has increased greatly in two stages. The 2004-2007 period grew at a rate of about 15\%, and 2007-2014 increased at a rate of about $8 \%$. Since 2015 , the growth rate of thermal power installed capacity has fallen to about $5 \%$.

Using this set of data, we can build a time series model. In this paper, two kinds of linear and nonlinear methods are used to predict the power installed capacity of China's thermal power in 2017-2026 years.

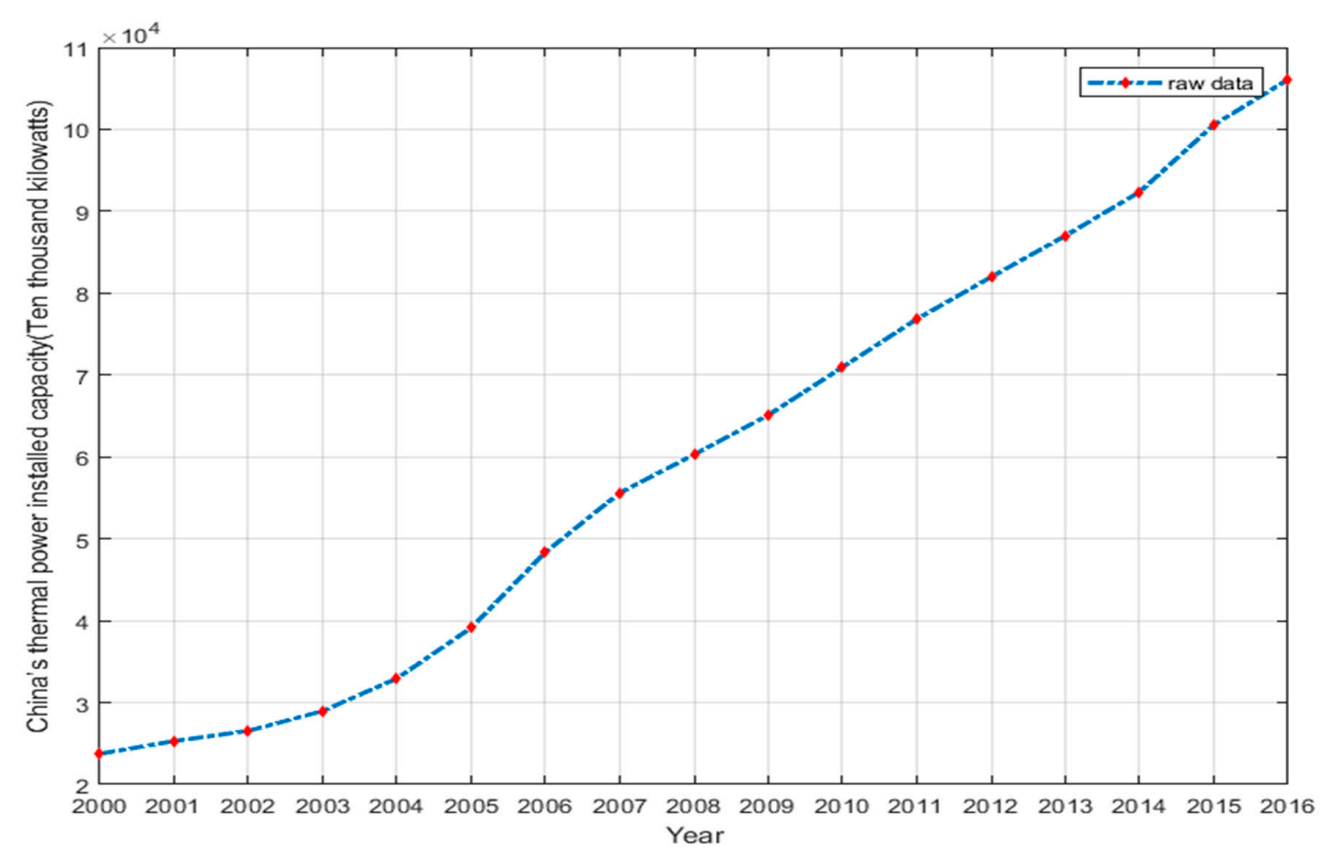

Figure 2. China's thermal power installed capacity period 2000-2016. Source: China Statistical Yearbook 2017 [46].

\subsection{Linear Parameters}

The linear regression model predicts the future data based on linear trend of the time series. Generally, the first-order accumulation sequence has a more obvious linearity. The curve of Figure 3 illustrates this point more. Therefore, we can use the MGM model to predict this cumulative sequence. 
When using the metabolic grey model for prediction, a series of operating parameters can be obtained. As mentioned above, ' $a$ ' and ' $b$ ' in Equation (6) are the operating coefficients of the MGM model. After calculation, the coefficients of the two are obtained as shown in Figure 4.

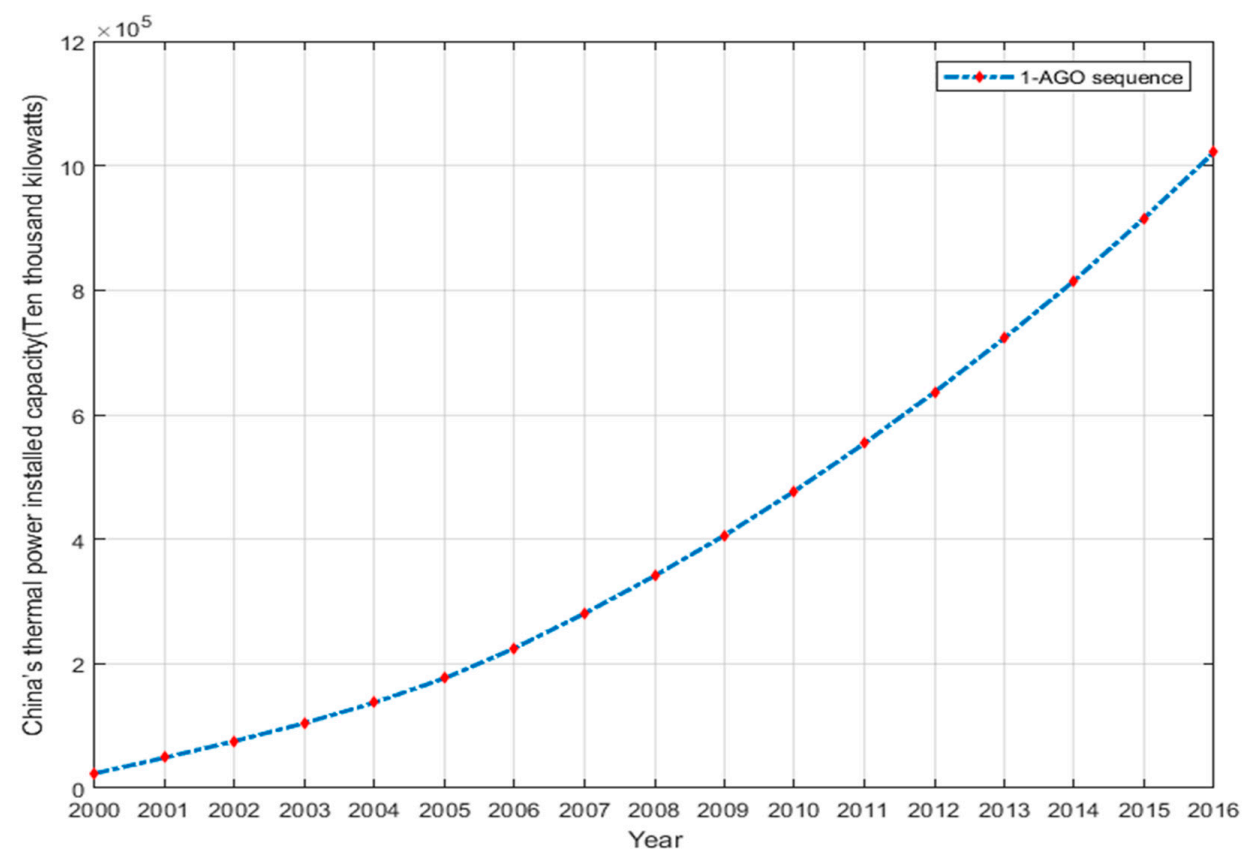

Figure 3. 1-AGO sequence of China's thermal power installed capacity.

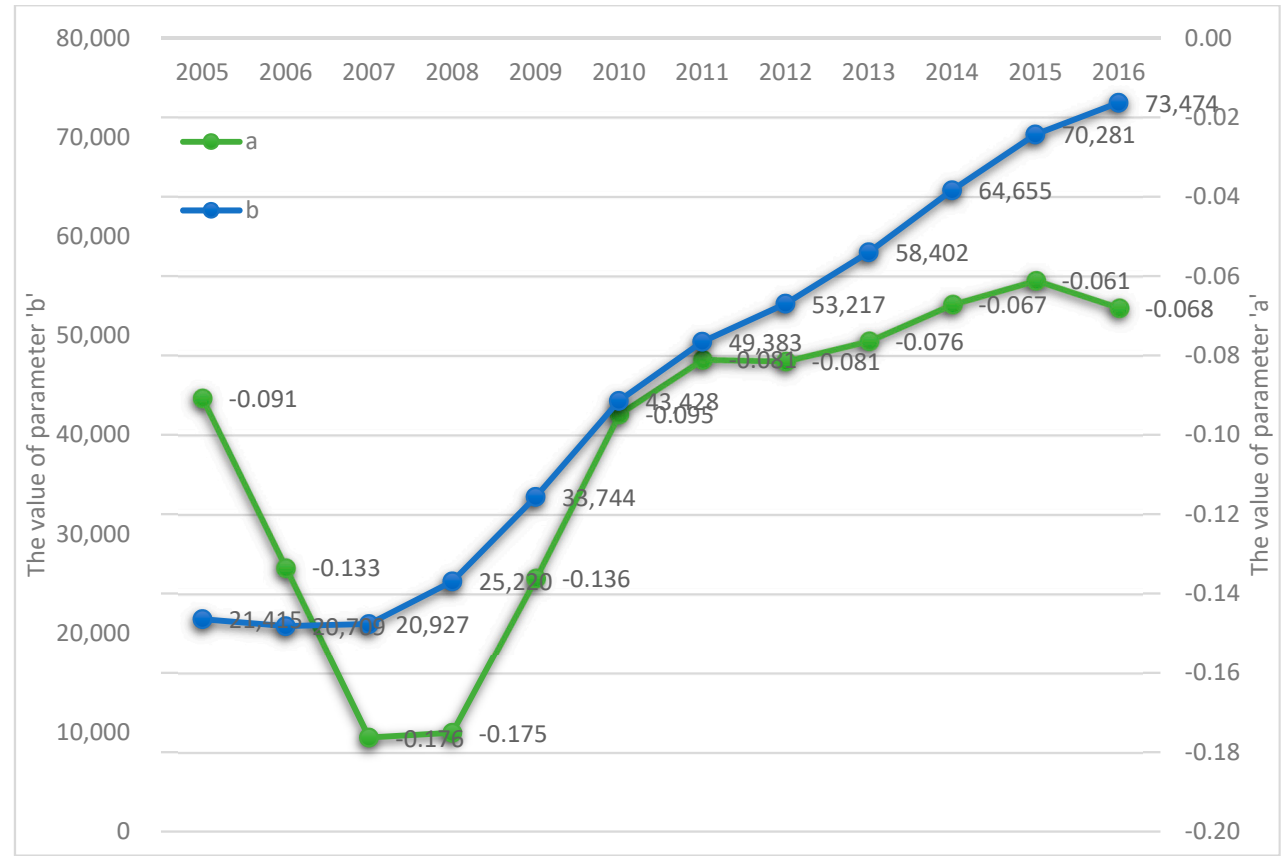

Figure 4. The value of MGM model's parameter.

\subsection{ARIMA Model Parameters}

The ARIMA model is used to predict stationary sequences. Differencing is a method of making a non-stationary sequence into a stationary one. In this study, our sequence becomes stable after 
zero-order difference. Then, the autocorrelation and partial autocorrelation plot will be drawn according to stationary sequence. With the help of EViews 7.2, our coefficients plot of original sequence is shown as Table 2. The autocorrelation coefficient showed a trailing edge, while the partial autocorrelation coefficient showed a first-order census. According to the coefficient judgment criteria of the ARIMA model, we judge ARIMA $(1,0,0)$ will be used to forecast in this study.

Table 2. Autocorrelation and partial autocorrelation coefficients of the original sequence.

\begin{tabular}{|c|c|c|c|c|c|c|}
\hline Autocorrelation & Partial Correlation & & $\mathrm{AC}^{*}$ & PAC $^{* *}$ & Q-Stat & Prob \\
\hline$|* * * * * *|$ &.$|* * * * * *|$ & 1 & 0.841 & 0.841 & 14.287 & 0.000 \\
\hline.$|* * * * *|$ &.$* 1.1$ & 2 & 0.671 & -0.126 & 23.980 & 0.000 \\
\hline.$|* * * *|$ & .1 .1 & 3 & 0.503 & -0.094 & 29.809 & 0.000 \\
\hline $.1^{* *} . \mid$ & .1 .1 & 4 & 0.332 & -0.121 & 32.547 & 0.000 \\
\hline $.1 * .1$ & .1 .1 & 5 & 0.164 & -0.117 & 33.272 & 0.000 \\
\hline .1 .1 & .1 .1 & 6 & 0.009 & -0.101 & 33.274 & 0.000 \\
\hline.$* 1.1$ & .1 .1 & 7 & -0.120 & -0.058 & 33.739 & 0.000 \\
\hline.$* *||$. &.$* 1.1$ & 8 & -0.224 & -0.068 & 35.543 & 0.000 \\
\hline.$* *||$. & .1 .1 & 9 & -0.314 & -0.101 & 39.530 & 0.000 \\
\hline.$* * 1.1$ & .1 .1 & 10 & -0.389 & -0.103 & 46.501 & 0.000 \\
\hline.$* * * 1.1$ & .1 .1 & 11 & -0.431 & -0.049 & 56.514 & 0.000 \\
\hline.$* * * 1.1$ & .1 .1 & 12 & -0.430 & 0.011 & 68.452 & 0.000 \\
\hline
\end{tabular}

Note: Columns 1 and 2 show the velocity trend of correlation coefficient that shrinks to two times the standard deviation (got by EViews 7.2). AC* means the value of autocorrelation coefficient. PAC** means the value of partial correlation coefficient.

In order to judge the goodness of fit for ARIMA $(1,0,0)$ model, we choose the value of R-squared, which is a statistically significant measure, to evaluate this model. As shown in Table 3 , the value of stationary R-squared is $0.994>0.60$. This shows that the ARIMA $(1,0,0)$ model selected in this paper is suitable for the prediction.

Table 3. Parameters of goodness of fit for ARIMA $(1,0,0)$ model.

\begin{tabular}{ccccc}
\hline \multirow{2}{*}{ Model } & \multirow{2}{*}{ Number of Predictors } & \multicolumn{2}{c}{ Model Fit Statistics } & \multirow{2}{*}{ Number of Outliers } \\
\cline { 3 - 4 } & 1 & Stationary R-Squared & R-Squared & \\
\hline ARIMA $(1,0,0)$ & 1 & 0.994 & 0.994 & 0 \\
\hline
\end{tabular}

Similarly, for the GM-ARIMA model, it is important to choose the right parameters. After repeated experiments, we finally chose the ARIMA $(2,0,1)$ model to predict the residual sequence. The goodness of fit of this model is shown in Table 4. In this table, the value of stationary R-squared is $0.67>0.6$, showing that the fitting effect is good.

Table 4. Parameters of goodness of fit for ARIMA $(2,0,1)$ model.

\begin{tabular}{ccccc}
\hline \multirow{2}{*}{ Model } & \multirow{2}{*}{ Number of Predictors } & \multicolumn{2}{c}{ Model Fit Statistics } & \multirow{2}{*}{ Number of Outliers } \\
\cline { 3 - 4 } & 1 & Stationary R-Squared & R-Squared & \\
\hline ARIMA $(2,0,1)$ & 1 & 0.670 & 0.670 & 0 \\
\hline
\end{tabular}

\subsection{Nonlinear Parameters}

As shown in Equation (13), the difference between the non-linear metabolic grey model and the general metabolic grey model lies in the addition of power coefficients. After MatLab's solution, the power coefficient of this nonlinear model is shown in Figure 5. We take those power coefficients into Equation (13) and make predictions based on the steps explained in the previous section. Final predictions can be obtained. 


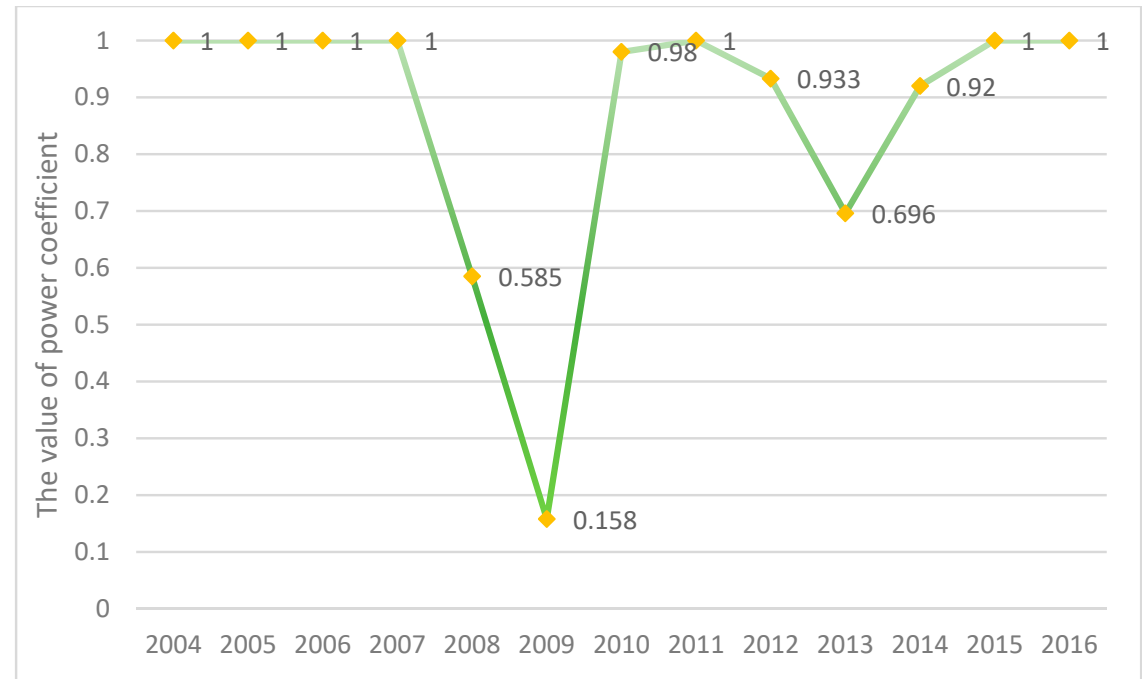

Figure 5. Display of power coefficients produced by NMGM model.

\subsection{Comparison and Evaluation of Multiple Models}

After calculation, the final prediction results of the four models are shown in Figure 6. In Figure 6, the black line is the initial data for 2000-2016, and the remaining four lines represent the fitted values of the four models, respectively. From the final fitting results, we can see that the difference between the four models and the original value is very small. The coincidence degree between the four fitted values and the original values also represents a certain persuasion of the prediction results of the four models adopted in this paper.

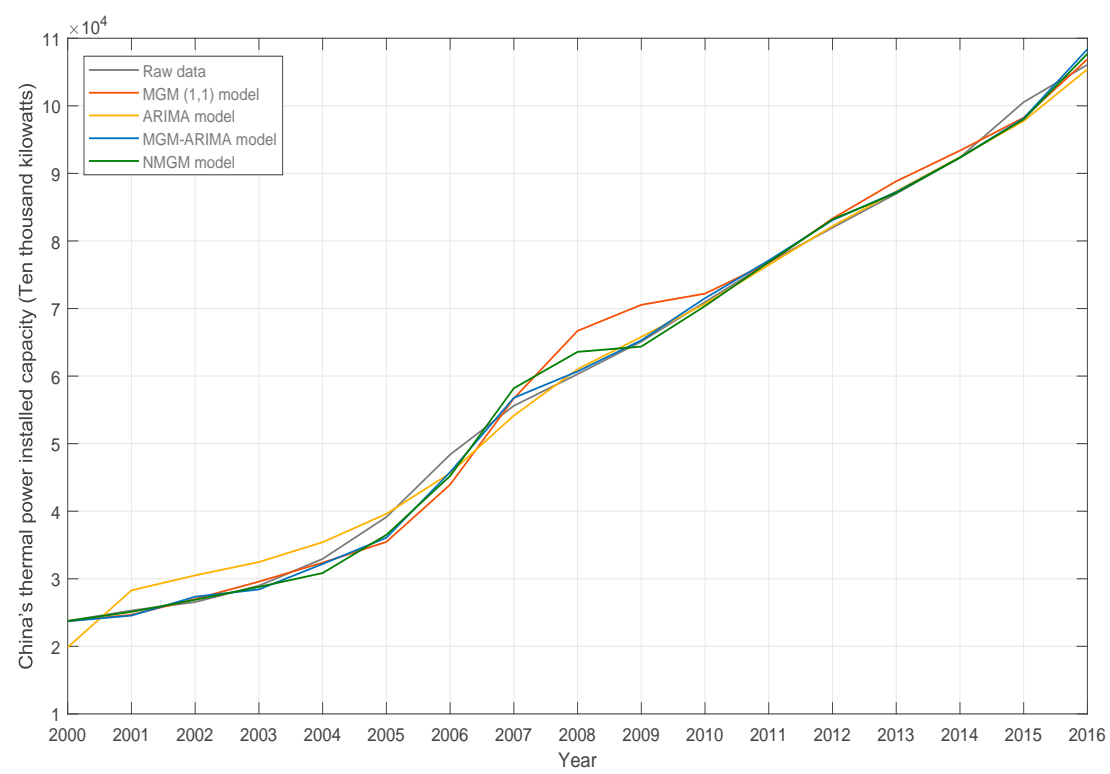

Figure 6. Gap of four models (MGM model, GM-ARIMA model, ARIMA model and NMGM model) between predicted and actual values.

We further use the data to illustrate the accuracy. We use the values of relative error to determine the goodness of the four models. The specific formula is as follows:

$$
\text { Goodness }=1-\mathrm{APE}=1-\frac{(\text { Predition }- \text { True data })}{\text { True data }}
$$


Figure 7 shows the prediction accuracy of the four models in each year. From the accuracy of the spider web we can see that the average accuracy of the four models is about $95 \%$. Although the accuracy varies from year to year, the lowest accuracy is also maintained above $80 \%$. It can be shown that the reliability of the four models is very high.

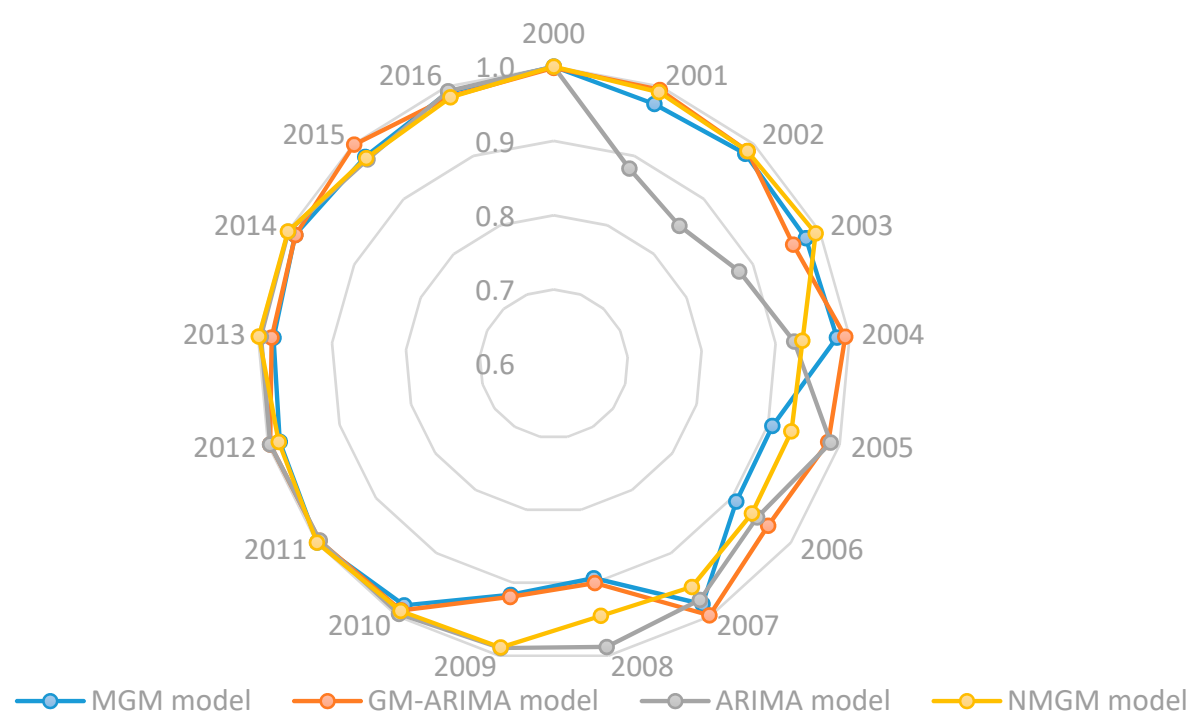

Figure 7. The fitting goodness value of multiple models at different time points.

We further judge it by numerical values. With the help of Formulas (19)-(21), we can calculate the values of MSE, MSPE and MAPE for each model (shown as Table 5). The values of the MAPE of the four models are all 2-4\%, and the values of MSPE are all less than 0.01. In particular, the MAPE of the GM-ARIMA model has reached $2.13 \%$, which is the smallest among the four. It is further demonstrated that the prediction accuracy of the four models is very high, and the results are worthy of trust.

Table 5. Error values of multiple models.

\begin{tabular}{lcccc}
\hline & Model 1 & Model 2 & Model 3 & Model 4 \\
\hline & MGM (1,1) & GM-ARIMA & ARIMA (1,0,0) & NMGM (1,1) \\
\hline MSE & $7,065,216.259$ & $4,567,384.561$ & $1,908,065.867$ & $2,984,472.666$ \\
MSPE & 0.002312295 & 0.005201106 & 0.000791596 & 0.001154194 \\
MAPE & $3.37 \%$ & $2.13 \%$ & $3.71 \%$ & $2.36 \%$ \\
\hline
\end{tabular}

\subsection{Forecast Results}

In this section, we will show the predictions in detail. It is predicted that in the next ten years, the trend chart of China's thermal power installed capacity will be as shown in Figure 8. Because the prediction results of each model are different; we choose an operator method with higher reliability to empower and integrate the four kinds of predictive values. The operator method gives high power coefficients for high accuracy at each point of time. The final result will be the most accurate prediction of the overall comprehensive accuracy. 


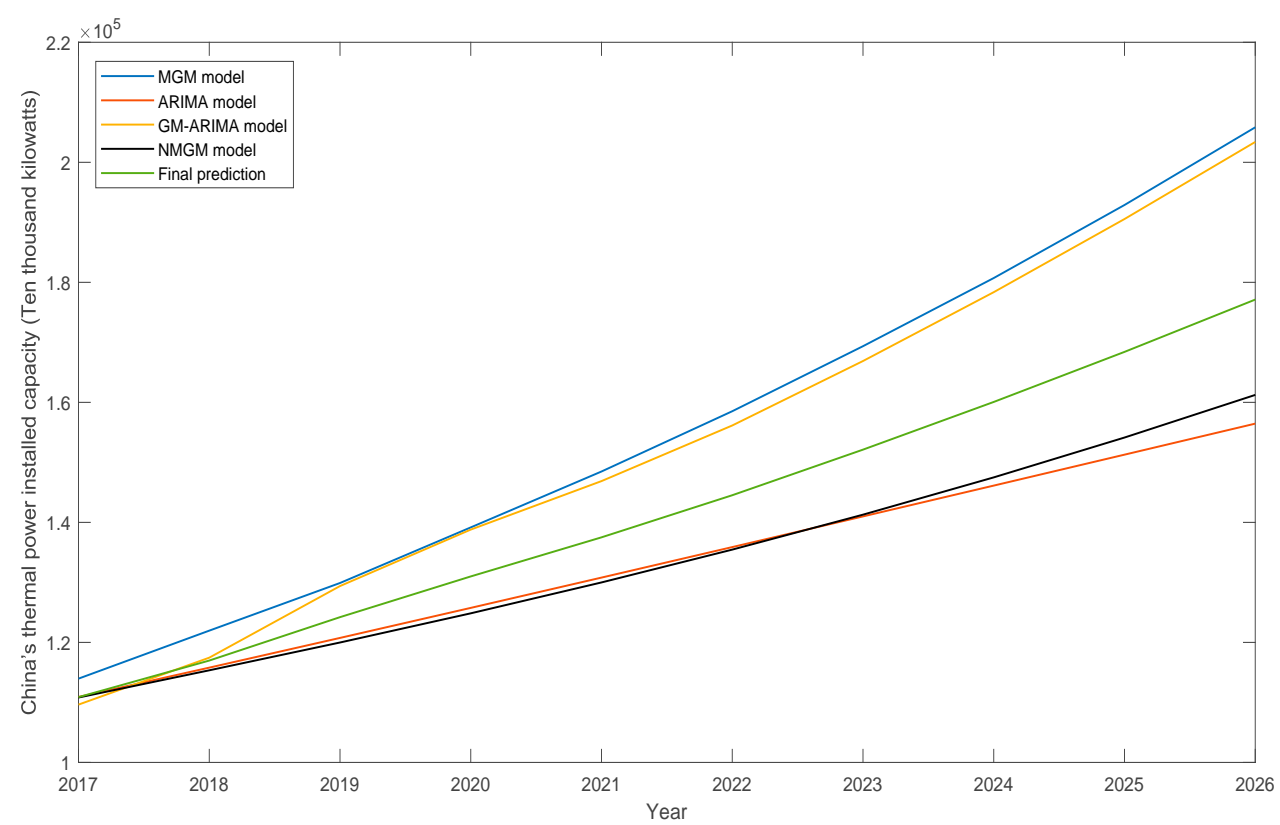

Figure 8. The predictions of the four models and the final prediction after the operator synthesis.

Table 6 shows the concrete results of the final forecast and the annual growth rate. In the next ten years, China's thermal power installed capacity will increase at an average rate of $5 \%$ a year.

Table 6. Forecast and growth rate of thermal power installed capacity in the next decade.

\begin{tabular}{ccc}
\hline Year & China's Thermal Power Installed Capacity/Ten Thousand Kilowatts & Annual Growth Rate \\
\hline 2017 & $110,879.2003$ & $4.51 \%$ \\
2018 & $116,974.6431$ & $5.50 \%$ \\
2019 & $124,207.3304$ & $6.18 \%$ \\
2020 & $130,993.5953$ & $5.46 \%$ \\
2021 & $137,507.0279$ & $4.97 \%$ \\
2022 & $144,522.9155$ & $5.10 \%$ \\
2023 & $152,121.2032$ & $5.26 \%$ \\
2024 & $160,069.2449$ & $5.22 \%$ \\
2025 & $168,409.0602$ & $5.21 \%$ \\
2026 & $177,125.3285$ & $5.18 \%$ \\
2017 & $110,879.2003$ & $5.50 \%$ \\
\hline
\end{tabular}

\section{Conclusions}

A comparison between linear and non-linear forecasting models can comprehensively describe the characteristics of the prediction data and provide multi-angle analysis for the prediction results. In this work, we combine linear (MGM, GM-ARIAMA, and ARIMA) and nonlinear (NMGM) time-series forecasting models to predict China's installed capacity of thermal power. The average relative errors of the MGM model, the GM-ARIMA model, the ARIMA model and the NMGM model were $3.37 \%, 2.13 \%$, $3.71 \%$ and $2.36 \%$ respectively, which indicate the proposed models can produce reliable computing results. The combination approach would be valuable for future related research.

The forecasting results show that China's coal-fired power plant installed capacity will increase by $5.26 \%$ a year (or 74 gigawatts) in the next ten years (from 2017 to 2026). Compared to this, the average annual growth rate of China's coal-fired power plant installed capacity increased by 8.80 a year (or 56 gigawatts) during 2007-2016. Therefore, the future average annual growth rate will be slower than the past decade, whereas the new added capacity in the future will much higher than the past decade. 
We suggest that the Chinese government should make more efforts in the following two aspects. The first is to improve the utilization of thermal power installed. Improving the utilization of thermal power installed means optimizing the mode of power generation on the source of thermal power. Secondly, the government should also note the development and utilization of renewable energy. Wind power, nuclear power generation and other clean energy generation should be actively promoted. Using a variety of power generation means reducing the pressure on thermal power. Only by combining the two can we strictly control the installed capacity of thermal power, improve the current status of energy generation and make a contribution to the world's carbon emission reduction.

Acknowledgments: This work is supported by the Initial Founding of Scientific Research for the Introduction of Talents of China University of Petroleum (East China) (YJ2016002) and the Fundamental Research Funds for the Central Universities (17CX05015B).

Author Contributions: Shuyu Li performed the experiments, analyzed the data, and contributed reagents/materials/analysis tools, and selected the data, Xue Yang and Rongrong Li conceived and designed the experiments and wrote the paper; All authors read and approved the final manuscript.

Conflicts of Interest: The authors declare no conflict of interest.

\section{References}

1. Edenhofer, O. King Coal and the queen of subsidies. Science 2015, 349, 1286-1287. [CrossRef] [PubMed]

2. Wang, Q.; Li, R. Decline in China's coal consumption: An evidence of peak coal or a temporary blip? Energy Policy 2017, 108, 696-701. [CrossRef]

3. Peters, G.P.; Andrew, R.M.; Canadell, J.G.; Fuss, S.; Jackson, R.B.; Korsbakken, J.I.; Le Quéré, C.; Nakicenovic, N. Key indicators to track current progress and future ambition of the Paris Agreement. Nat. Clim. Chang. 2017, 7, 118-122. [CrossRef]

4. Steckel, J.C.; Edenhofer, O.; Jakob, M. Drivers for the renaissance of coal. Proc. Natl. Acad. Sci. USA 2015, 112, E3775-E3781. [CrossRef] [PubMed]

5. Chu, S.; Majumdar, A. Opportunities and challenges for a sustainable energy future. Nature 2012, 488, 294-303. [CrossRef] [PubMed]

6. Wang, Q.; Li, R. Journey to burning half of global coal: Trajectory and drivers of China's coal use. Renew. Sustain. Energy Rev. 2016, 58, 341-346. [CrossRef]

7. González-Eguino, M.; Olabe, A.; Ribera, T. New coal-fired plants jeopardise Paris agreement. Sustainability 2017, 9, 168. [CrossRef]

8. Wang, Q.; Chen, X. China's electricity market-oriented reform: From an absolute to a relative monopoly. Energy Policy 2012, 51, 143-148. [CrossRef]

9. Wang, Q.; Li, R. Drivers for energy consumption: A comparative analysis of China and India. Renew. Sustain. Energy Rev. 2016, 62, 954-962. [CrossRef]

10. Zhao, Y.; Wang, S.; Duan, L.; Lei, Y.; Cao, P.; Hao, J. Primary air pollutant emissions of coal-fired power plants in China: Current status and future prediction. Atmos. Environ. 2008, 42, 8442-8452. [CrossRef]

11. You, C.; Xu, X. Coal combustion and its pollution control in China. Energy 2010, 35, 4467-4472. [CrossRef]

12. Wang, Q.; Chen, X. Energy policies for managing China's carbon emission. Renew. Sustain. Energy Rev. 2015, 50, 470-479. [CrossRef]

13. Zing, N.; Ding, Y.; Pan, J.; Wang, H.; Gregg, J. Climate change-the Chinese challenge. Science 2008, 319, 730-731. [CrossRef] [PubMed]

14. Wang, Q. Effective policies for renewable energy—-The example of China's wind power-Lessons for China's photovoltaic power. Renew. Sustain. Energy Rev. 2010, 14, 702-712. [CrossRef]

15. Biello, D. How much will tar sands oil add to global warming. Sci. Am. 2013, 23, 1-5.

16. Zhou, L.; Yong, X.L. Electricity Demand Forecasting Based on ARIMA Model and Linear Neural Network. J. Ludong Univ. 2015, 3, 89-94.

17. Panklib, K.; Prakasvudhisarn, C.; Khummongkol, D. Electricity Consumption Forecasting in Thailand Using an Artificial Neural Network and Multiple Linear Regression. Energy Sources Part B 2015, 10, 427-434. [CrossRef] 
18. Hsu, C.C.; Chen, C.Y. Applications of improved grey prediction model for power demand forecasting. Energy Convers. Manag. 2003, 44, 2241-2249. [CrossRef]

19. Zhao, H.; Guo, S. An optimized grey model for annual power load forecasting. Energy 2016, 107, $272-286$. [CrossRef]

20. Cui, Z.; Li, L.; Zhao, C.; Yang, T. Traffic Analysis and Forecasting of Power Video Services Based on ARIMA Model. J. Tianjin Univ. 2015, 48, 49-55.

21. Adhikari, R. A neural network based linear ensemble framework for time series forecasting. Neurocomputing 2015, 157, 231-242. [CrossRef]

22. Aiello, G.; Cannizzaro, L.; Scalia, G.L.; Muriana, C. An expert system for vineyard management based upon ubiquitous network technologies. Int. J. Serv. Oper. Inform. 2011, 6, 230-247. [CrossRef]

23. Muriana, C.; Piazza, T.; Vizzini, G. An expert system for financial performance assessment of health care structures based on fuzzy sets and KPIs. Knowl. Based Syst. 2016, 97, 1-10. [CrossRef]

24. Chen, S.P.; Dang, J.F. A variable spread fuzzy linear regression model with higher explanatory power and forecasting accuracy. Inf. Sci. 2008, 178, 3973-3988. [CrossRef]

25. D'Urso, P.; Santoro, A. Goodness of fit and variable selection in the fuzzy multiple linear regression. Fuzzy Sets Syst. 2006, 157, 2627-2647. [CrossRef]

26. Dudek, G. Pattern-based local linear regression models for short-term load forecasting. Electr. Power Syst. Res. 2016, 130, 139-147. [CrossRef]

27. Sun, H.; Liu, H.; Xiao, H.; He, R.; Ran, B. Use of Local Linear Regression Model for Short-Term Traffic Forecasting. Transp. Res. Rec. J. Transp. Res. Board 2003, 1836, 143-150. [CrossRef]

28. Shamim, M.A.; Hassan, M.; Ahmad, S.; Zeeshan, M. A comparison of Artificial Neural Networks (ANN) and Local Linear Regression (LLR) techniques for predicting monthly reservoir levels. KSCE J. Civ. Eng. 2016, 20, 971-977. [CrossRef]

29. Wang, G.; Su, Y.; Shu, L. One-day-ahead daily power forecasting of photovoltaic systems based on partial functional linear regression models. Renew. Energy 2016, 96, 469-478. [CrossRef]

30. Sun, Y.; Wang, F.; Zhen, Z.; Mi, Z.; Liu, C.; Wang, B.; Lu, J. Research on short-term module temperature prediction model based on BP neural network for photovoltaic power forecasting. In Proceedings of the Power \& Energy Society General Meeting, Denver, CO, USA, 26-30 July 2015; pp. 1-5.

31. Li, J.; Yu, L. Using BP nerual networks for the simulation of energy consumption. In Proceedings of the Institute of Electrical and Electronics Engineers (IEEE) International Conference on Systems, Man and Cybernetics, San Diego, CA, USA, 5-8 October 2014; pp. 3542-3547.

32. Kang, H.B.; Liu, R.M.; Hou, X.M. Research of power forecasting model of photovoltaic power system based on neural network. Chin. J. Power Sources 2013, 3, 114-116.

33. Tsekouras, G.J.; Dialynas, E.N.; Hatziargyriou, N.D.; Kavatza, S. A non-linear multivariable regression model for midterm energy forecasting of power systems. Electr. Power Syst. Res. 2007, 77, 1560-1568. [CrossRef]

34. Kourkoutas, D.; Karanasiou, I.S.; Tsekouras, G.J.; Moshos, M.; Iliakis, E.; Georgopoulos, G. Glaucoma risk assessment using a non-linear multivariable regression method. Comput. Methods Progr. Biomed. 2012, 108, 1149-1159. [CrossRef] [PubMed]

35. Abushikhah, N.; Elkarmi, F.; Aloquili, O.M. Medium-Term Electric Load Forecasting Using Multivariable Linear and Non-Linear Regression. Smart Grid Renew. Energy 2011, 2, 126-135. [CrossRef]

36. Wang, Z.X.; Ye, D.J. Forecasting Chinese carbon emissions from fossil energy consumption using non-linear grey multivariable models. J. Clean. Prod. 2017, 142, 600-612. [CrossRef]

37. Zhong, T.; Guo, W.; Wang, D.; Du, Y. A Novel Nonlinear Grey Bernoulli Forecast Model NGBM $(1,1)$ of Underground Pressure for Working Surface. Electron. J. Geotech. Eng. 2011, 16, 1441-1450.

38. Ning, Y.; Fan, Y.; Fang, X.; Department, B.E. Water-Saving Irrigation Area of Nonlinear Combination Forecast Based on Grey Model. Henan Sci. 2016, 8, 176-181.

39. Chen, C.I.; Chen, H.L.; Chen, S.P. Forecasting of foreign exchange rates of Taiwan's major trading partners by novel nonlinear Grey Bernoulli model $\operatorname{NGBM}(1,1)$. Commun. Nonlinear Sci. Numeri. Simul. 2008, 13, 1194-1204. [CrossRef]

40. Chen, S.; Jeong, K.; Härdle, W.K. Recurrent support vector regression for a non-linear ARMA model with applications to forecasting financial returns. Comput. Stat. 2015, 30, 821-843. [CrossRef]

41. Ludlow, J.; Enders, W. Estimating non-linear ARMA models using Fourier coefficients. Int. J. Forecast. 2000, 16, 333-347. [CrossRef] 
42. Deng, J. Grey System Fundamental Method; Huazhong University of Science and Technology: Wuhan, China, 1982.

43. Wei, L.; Xu, Y.; Chen, C.; Wang, S.; Zhao, R.; Zhang, Y.; Ren, Z. Application of ARIMA Model in Traffic Accident Prediction. J. Beijing Univ. Technol. 2007, 20, 287-288.

44. Li, S.; Li, R. Comparison of forecasting energy consumption in Shandong, China Using the ARIMA model, GM model, and ARIMA-GM model. Sustainability 2017, 9, 1181. [CrossRef]

45. Wang, R.; You, Y. Solution of Nonlinear Gompertzlan Gray Model and Its Application. Shopp. Mall Mod. 2017, 17, 19-20.

46. National Bureau of Statistics of People's Republic of China (NBSC). China Statistical Yearbook; China Statistical Press: Beijing, China, 2017.

C 2018 by the authors. Licensee MDPI, Basel, Switzerland. This article is an open access article distributed under the terms and conditions of the Creative Commons Attribution (CC BY) license (http://creativecommons.org/licenses/by/4.0/). 